\title{
Effect of atorvastatin and metformin combination therapy in type 2 diabetic dyslipidemias
}

\author{
Ramsha Saman*, Margaret Voila
}

Department of Pharmacology, Gandhi Medical College, Secunderabad, Telangana, India

\author{
Received: 17 February 2020 \\ Revised: 02 June 2020 \\ Accepted: 06 June 2020 \\ *Correspondence: \\ Dr. Ramsha Saman, \\ Email: simplesaman.28@gmail.com
}

Copyright: $@$ the author(s), publisher and licensee Medip Academy. This is an open-access article distributed under the terms of the Creative Commons Attribution Non-Commercial License, which permits unrestricted non-commercial use, distribution, and reproduction in any medium, provided the original work is properly cited.

\begin{abstract}
Background: Dyslipidaemia is a major risk factor for cardiovascular complications in patients with type 2 diabetes mellitus and affects $10-73 \%$ of this population. In type 2 diabetes mellitus, increased efflux of free fatty acids from adipose tissue and impaired insulin mediated skeletal muscle uptake of free fatty acids, increases fatty acid flux to the liver and also decreased glucose utilization in muscle that leads to acute elevation of free fatty acids. Lipid profile which is altered in diabetes state is one of the significant factors in development of cardiovascular diseases. The derangements seen in serum lipid profile includes: increased total cholesterol (TC), triglycerides (TG) and lowdensity lipoprotein (LDL) and decreased high-density lipoprotein cholesterol (HDL) concentration. Hence with the aforementioned views the present study had been planned to evaluate the effect of atorvastatin and metformin combination therapy in type 2 diabetic dyslipidemias.

Methods: Study design, observational prospective study, with duration of 4-5 months and sample size of 30 patients with type 2 diabetes mellitus are taken with mild to moderate dyslipidemias. The study subjects received combination therapy of metformin $500 \mathrm{mg}$ /day along with atorvastatin $20 \mathrm{mg} /$ day, there effect is seen on serum lipid profile and fasting blood glucose levels (FBS).

Results: There was a significant mean decrease in TC, LDL , TG, FBS by $31.7 \mathrm{mg} / \mathrm{dl}$ (p<0.05), $28.5 \mathrm{mg} / \mathrm{dl}$ (p value $<0.05), 19.5 \mathrm{mg} / \mathrm{dl}(\mathrm{p}<0.05), 9.13 \mathrm{mg} / \mathrm{dl}(\mathrm{p}<0.05)$ respectively and rise in HDL by $1.7 \mathrm{mg} / \mathrm{dl}(\mathrm{p}<0.05))$, no significant decrease in VLDL $(\mathrm{p}>0.05)$.

Conclusions: Combination of atorvastatin and metformin was effective in reduction of TC, LDL, TG and FBS and elevation of HDL levels in type-2 diabetic dyslipidemias.
\end{abstract}

Keywords: Dyslipidemias, Type-2 diabetes mellitus, Atorvastatin, Metformin, Lipid profile, Fasting blood glucose

\section{INTRODUCTION}

Diabetes mellitus is a mumgltifaceted disease which is characterized by hyperglycemia, lipoprotein abnormalities and altered intermediary metabolism, and generation of free radicals often worsen the complications of diabetes mellitus. ${ }^{1}$ The global prevalence of diabetes among adults over 18 years of age has risen from $4.7 \%$ in 1980 to $8.5 \%$ in $2014 .^{2}$ Type 2 diabetes often accompanies along with other metabolic abnormalities such as obesity, hypertension and hypercoagulability, this group of eccentric abnormalities has been referred to as the metabolic syndrome and it has been related with high risk for atherosclerosis. ${ }^{3}$

The major risk factor for cardiovascular complications in patients with type-2 diabetes mellitus (T2 DM) is dyslipidaemia and it affects $10-73 \%$ of this population. ${ }^{4}$ Diabetic dyslipidemias commonly manifests as raised low-density lipoprotein cholesterol (LDL-C), decreased 
high-density lipoprotein cholesterol (HDL-C) levels, elevated triglyceride (TG) levels. In type-2 diabetes mellitus and insulin resistance, increased efflux of free fatty acids from adipose tissue and impaired insulin mediated skeletal muscle uptake of free fatty acids increases fatty acid flux to the liver and also decreased glucose utilization in muscle was analogous with elevation of free fatty acids. 5,6

The present study had been planned to evaluate the effect of atorvastatin and metformin combination therapy in type-2 diabetic dyslipidemias which is given as first line treatment in the management of dyslipidemias. ${ }^{7}$

\section{METHODS}

This was an observational prospective study, study period from November 2018 to March 2019. The present study was started after obtaining approval from the Institutional Ethics Committee, Gandhi Medical College. Patients were explained about study purpose and procedure, after screening 30 patients were enrolled and written informed consent was obtained from every patient.

\section{Inclusion criteria}

Inclusion criteria were patients with type-2 diabetes mellitus in the age group of 35-65 years, both sexes, only type-2 diabetes mellitus patients on oral hypoglycemic drugs with FBS $>110-<250 \mathrm{mg} / \mathrm{dl}$, and patients with mild to moderate dyslipidemias.

\section{Exclusion criteria}

Exclusion criteria were patients with type-1 diabetes mellitus and with type-2 diabetes mellitus on insulin, patients with uncontrolled diabetes (FBS >250 mg/dl) and uncontrolled hypertension (sys >160 and diastolic $>100$ ) and gestational diabetes mellitus.

After baseline investigations (lipid profile, FBS), patients were started on atorvastatin $20 \mathrm{mg}$ OD and metformin $500 \mathrm{mg}$ OD by the clinician and the follow up was done after 12 weeks to see their effect on lipid profile and FBS.

\section{Statistical analysis}

Data was collected, tabulated and analysed by using SPSS software with appropriate statistical tests. Paired $\mathrm{t}$ test was applied to compare values before and after 12 weeks treatment parameters and $\mathrm{p}$ (probability) value obtained is used to quantify statistical significance of evidence.

\section{RESULTS}

There was a significant mean decrease in TC, LDL, TG, FBS by $31.7 \mathrm{mg} / \mathrm{dl}(\mathrm{p}<0.05), 28.5 \mathrm{mg} / \mathrm{dl}$ (p value <0.05), $19.5 \mathrm{mg} / \mathrm{dl}(\mathrm{p}<0.05), 9.13 \mathrm{mg} / \mathrm{dl}(\mathrm{p}<0.05)$ respectively and rise in HDL by $1.7 \mathrm{mg} / \mathrm{dl}(\mathrm{p}<0.05)$, no significant decrease in VLDL $(\mathrm{p}>0.05)$. The combination therapy of metformin $20 \mathrm{mg}$ and atorvastatin $500 \mathrm{mg}$ for 12 weeks resulted in fall of TC by $13.8 \%$, decrease in LDL by $19.4 \%$ and reduction in TG by $12.3 \%$ and decline in fasting blood sugar FBS by $6.4 \%$ and rise in HDL by $4 \%$.

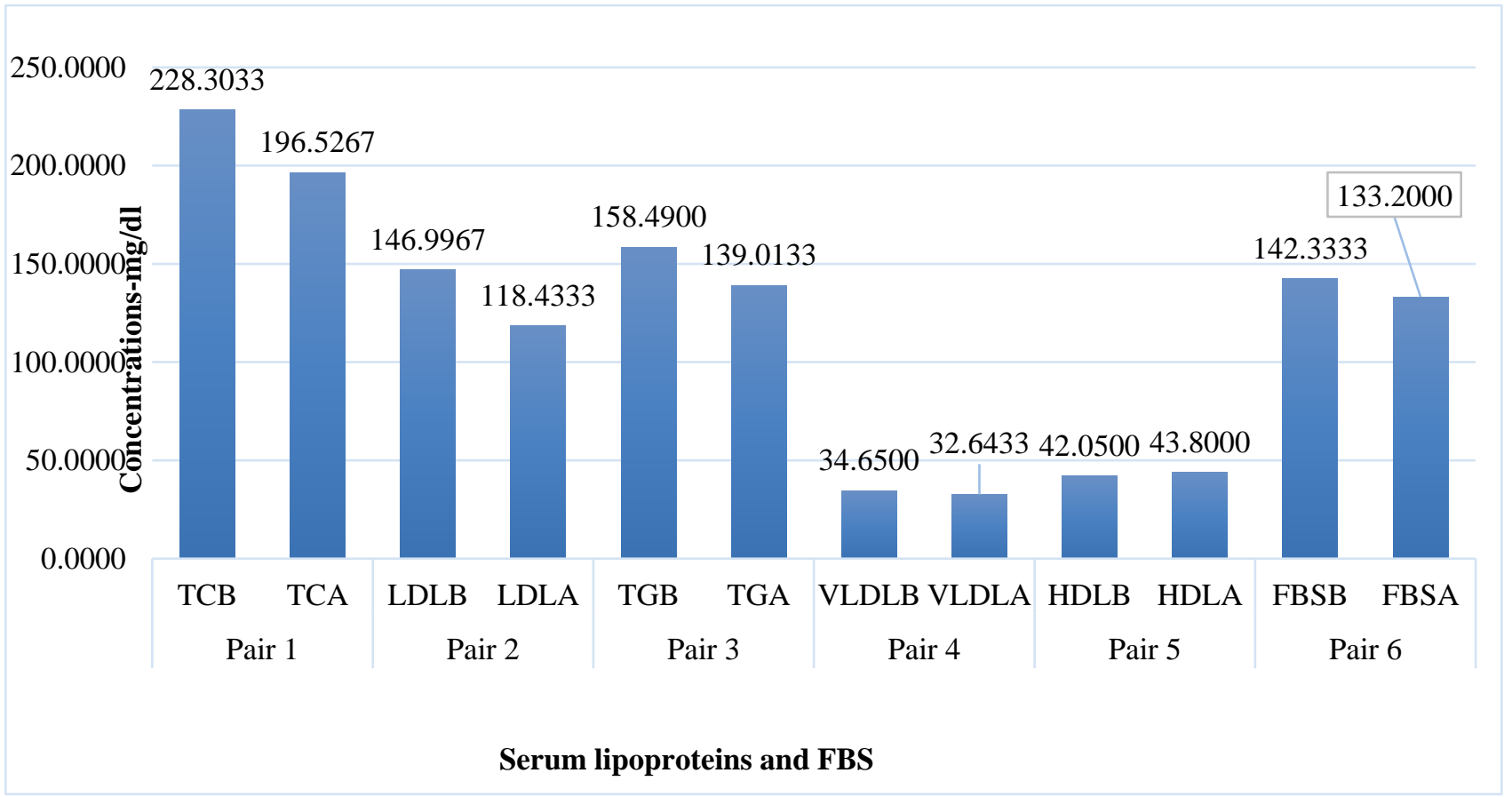

Figure 1: The mean variations of serum lipoproteins and fasting blood sugar at (A) baseline using paired t-test and (B) after 12 weeks of treatment. 
Table 1: Paired samples statistics.

\begin{tabular}{|llllll|}
\hline Variables & & Mean & N & SD & SEM \\
\hline \multirow{2}{*}{ Pair 1 } & TCB & 228.3033 & 30 & 22.48395 & 4.10499 \\
\cline { 2 - 6 } & TCA & 196.5267 & 30 & 17.38265 & 3.17362 \\
\hline \multirow{2}{*}{ Pair 2 } & LDLB & 146.9967 & 30 & 27.46366 & 5.01416 \\
\cline { 2 - 6 } & LDLA & 118.4333 & 30 & 19.11252 & 3.48945 \\
\hline \multirow{2}{*}{ Pair 3 } & TGB & 158.4900 & 30 & 38.65555 & 7.05750 \\
\cline { 2 - 6 } & TGA & 139.0133 & 30 & 33.46350 & 6.10957 \\
\hline \multirow{2}{*}{ Pair 4 } & VLDLB & 34.6500 & 30 & 13.01624 & 2.37643 \\
\cline { 2 - 6 } Pair 5 & VLDLA & 32.6433 & 30 & 9.65072 & 1.76197 \\
\hline \multirow{2}{*}{ Pair 6 } & HDLB & 42.0500 & 30 & 9.89273 & 1.80616 \\
\cline { 2 - 6 } & HDLA & 43.8000 & 30 & 9.19295 & 1.67840 \\
\cline { 2 - 6 } & FBSB & 142.3333 & 30 & 36.88177 & 6.73366 \\
\hline
\end{tabular}

\section{DISCUSSION}

Diabetes mellitus is associated with a considerably increased risk of premature atherosclerotic cardiovascular disease. Intensive glycemic control has essentially failed to significantly improve cardiovascular outcomes in clinical trials. Dyslipidemia is common in diabetes and there is strong evidence that cholesterol lowering improves cardiovascular outcomes, even in patients with apparently unremarkable lipid profiles.

Statins are the first line therapy to reduce atherosclerotic cardio vascular disease by decreasing LDL-C by $30-49 \%$ or at least $50 \%$ depending on risk level in diabetic dylipidemias. ${ }^{8}$ Metformin is the first line drug in type-2 diabetes mellitus. The combination of metformin and atorvastatin is synergistic as metformin enhances the antiadipogenic effects of atorvastatin. Metformin increase atorvastatin mediated inhibition of STAT3 signaling and metformin enhances atorvastatin mediated TGF- $\beta / \mathrm{Smad} 3$ signaling. ${ }^{9}$ In present study we found the combination of atorvastatin and metformin was effective in reduction of TC, LDL, TG and FBS and elevation of HDL levels in type-2 diabetic dyslipidemias.

In a study conducted by Balsubramanian et al to assess efficacy, safety and tolerability of a fixed dose combination of atorvastatin $10 \mathrm{mg}$ and metformin SR 500 $\mathrm{mg}$ in adult Indian patients with diabetic dyslipidaemia. ${ }^{10}$ Therapy with the fixed dose combination of atorvastatin $10 \mathrm{mg}$ and metformin SR $500 \mathrm{mg}$ resulted in a significant reduction in the mean plasma fasting and postprandial glucose levels (35 and $38.8 \%$ respectively) and there was a steep fall in the HbA1c levels from baseline levels of $8.76 \%$ to $6.74 \%(23.1 \%)$. In present study the combination therapy of metformin $20 \mathrm{mg}$ and atorvastatin $500 \mathrm{mg}$ for 12 weeks resulted in fall of fasting blood sugar (FBS) by $6.4 \%$ and HbA1c could not be done due to financial constraints.

In a study conducted by Balsubramanian et al there was also a significant $(\mathrm{p}<0.05)$ reduction in mean total cholesterol $31.2 \%$, LDL cholesterol $35.4 \%$, VLDL cholesterol $19.6 \%$ and a significant increase HDL cholesterol $9.5 \% .{ }^{10}$ In present study there was also a significant reduction in mean total cholesterol $13.8 \%$, LDL cholesterol $19.4 \%$, TG $12.3 \%$ and a rise in HDL cholesterol $4 \%$. In both the aforementioned studies there was a significant decline in following parameters FBS, TC, LDL, TG, and a moderate rise in HDL with the combination therapy of metformin and atorvastatin.

\section{CONCLUSION}

It can be concluded that combination therapy is more efficacious than monotherapy. The enhanced effect of combination could be due to beneficial pleotropic effects of atorvastatin improving endothelial function, decreasing oxidative stress and inflammation, and inhibiting the thrombogenic response. However, more studies are required to confirm our findings and provide conclusive results regarding the potential benefit from combined treatment of atorvastatin and metformin in patients with type-2 diabetes mellitus.

\section{ACKNOWLEDGEMENTS}

I would express my gratitude to Dr. Vijay Shekhar, HOD of Endocrinology to allow my study in his department. I would thank my guide Dr. Margaret Voila, Associate Professor, Department of Pharmacology, Gandhi Medical College. I would also be grateful to assistant professors Dr. Mary Rohini and Dr. Suguna for their support throughout my study.

Funding: No funding sources

Conflict of interest: None declared

Ethical approval: The study was approved by the Institutional Ethics Committee

\section{REFERENCES}

1. Kathore VR, Bansode DG. The effect of vitamin C on fasting blood glucose level and lipid profile in type-2 diabetes mellitus patients. Int J Recent Trends Science Technology. 2015;16(3):585-90. 
2. Sarwar N, Gao P, Seshasai SR. Diabetes mellitus, fasting blood glucose concentration, and risk of vascular disease: a collaborative meta-analysis of 102 prospective studies. Emerging Risk Factors Collaboration. 2010;26(375):2215-22.

3. DeFronzo RA, Ferrannini E. Insulin resistance: a multifaceted syndrome responsible for NIDDM, obesity, hypertension, dyslipidemia, and atherosclerotic cardiovascular disease. Diabetes Care. 1991;14(3):173-94.

4. Mithal A, Majhi D, Shunmugavelu M. Prevalence of dyslipidemia in adult Indian diabetic patients: a cross sectional study (SOLID). Indian J Endocrinol Metab. 2014;18(5):642-7.

5. Boden G. Role of fatty acids in the pathogenesis of insulin resistance and NIDDM. Diabetes. 1997;46:310 .

6. Kelley DE, Simoneau JA. Impaired free fatty acid utilization by skeletal muscle in non-insulindependent diabetes mellitus. J Clin Invest 1994;94:2349-56.

7. Management of Dyslipidemia in Adults with Diabetes American Diabetes Association Diabetes Care. 2003;26:83-6.
8. Vaughan CJ, Gotto AM, Basson CT. The evolving role of statins in the management of atherosclerosis. $\mathrm{J}$ Am Coll Cardiol. 2000;35:1-10.

9. Kim BH, Han S, Lee H, Park CH, Chung YM, Shin $\mathrm{K}$, et al. Metformin enhances the anti-adipogenic effects of atorvastatin via modulation of STAT3 and TGF- $\beta /$ Smad3 signaling. Biochemical Biophysical Res Communications. 2015;456(1):173-8.

10. Balasubramanian R, Varadharajan S, Kathale A, Nagraj LM, Periyandavar I, Nayak UP, et al. Assessment of the efficacy and tolerability of a fixed dose combination of atorvastatin $10 \mathrm{mg}$ and metformin SR $500 \mathrm{mg}$ in diabetic dyslipidaemia in adult Indian patients. Journal Indian Med Association. 2008;106(7):464-7.

Cite this article as: Saman R, Voila M. Effect of atorvastatin and metformin combination therapy in type 2 diabetic dyslipidemias. Int J Basic Clin Pharmacol 2020;9:1069-72. 